\title{
Multiobjective optimization of multipass turning machining process using the Genetic Algorithms solution
}

Patrick Ejebheare AMIOLEMHEN, Joshua Ahurome ESEIGBE

DOI: $10.30464 /$ jmee.2019.3.2.97

Cite this article as:

Amiolemhen P.,E., Eseigbe J. A. Multiobjective optimization of multipass turning machining process using the Genetic Algorithms solution. Journal of Mechanical and Energy Engineering, Vol. 3(43), No. 2, 2019, pp. 97-108.

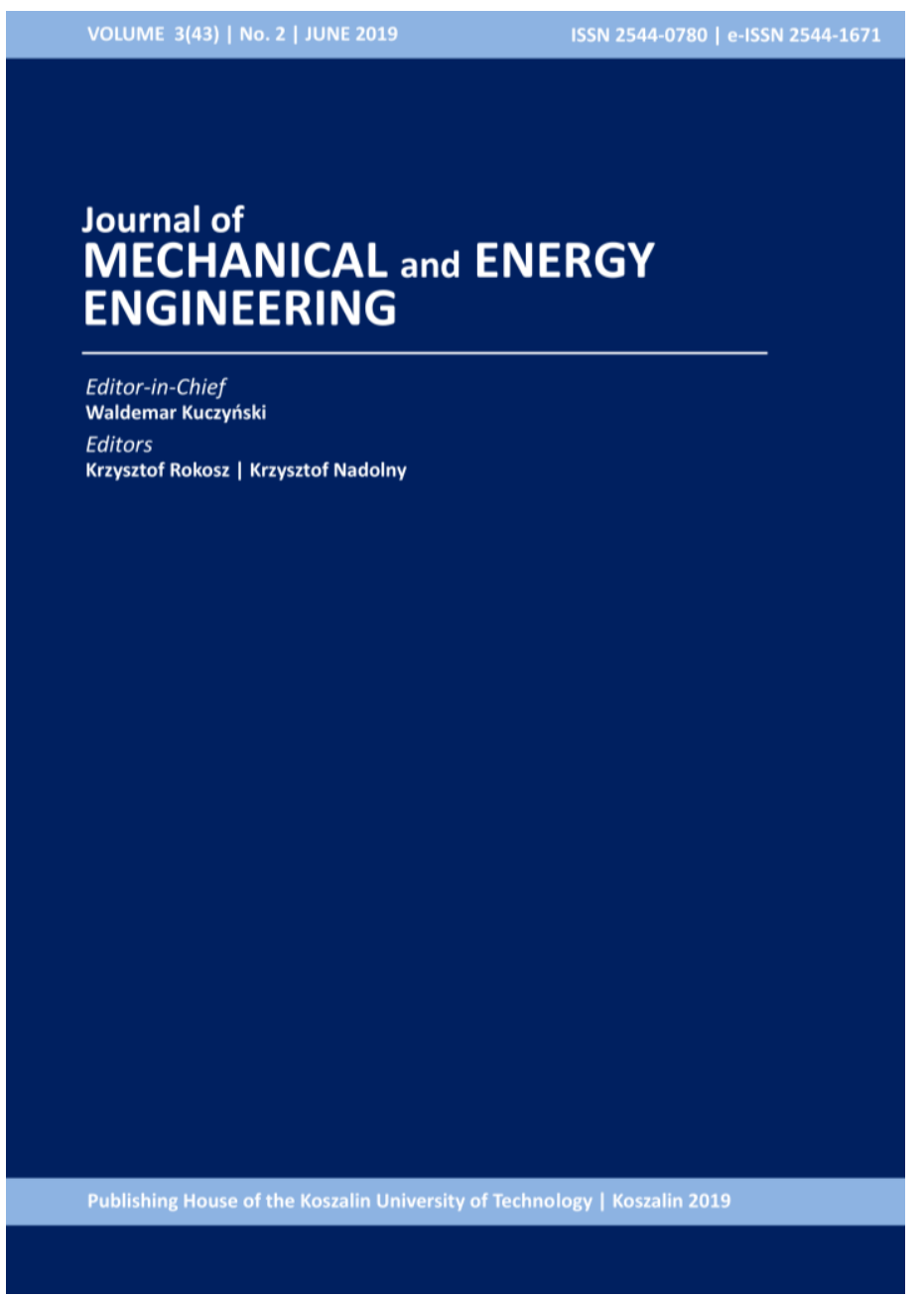

Journal of Mechanical and Energy Engineering

Website: jmee.tu.koszalin.pl

ISSN (Print): 2544-0780

ISSN (Online): 2544-1671

Volume: 3(43)

Number: 2

Year: 2019

Pages: 97-108

Article Info:

Received 21 May 2019

Accepted 11 June 2019

\section{Open Access}

This article is distributed under the terms of the Creative Commons Attribution 4.0 (CC BY 4.0) International License (http://creativecommons.org/licenses/by/4.0/), which permits unrestricted use, distribution, and reproduction in any medium, provided you give appropriate credit to the original author(s) and the source, provide a link to the Creative Commons license, and indicate if changes were made. 


\title{
MULTIOBJECTIVE OPTIMIZATION OF MULTIPASS TURNING MACHINING PROCESS USING THE GENETIC ALGORITHMS SOLUTION
}

\author{
Patrick Ejebheare AMIOLEMHEN $^{1^{*}}$, Joshua Ahurome ESEIGBE ${ }^{1}$ \\ ${ }^{1}$ Department of Production, Faculty of Engineering, University of Benin, P.M.B 1154, Benin City, Nigeria, \\ e-mail - patrick.amiolemhen@uniben.edu
}

(Received 21 May 2019, Accepted 11 June 2019)

\begin{abstract}
The study involves the development of multi-objective optimization model for turning machining process. This model was developed using a GA - based weighted-sum of minimum production cost and time criteria of multipass turning machining process subject to relevant technological/practical constraints. The results of the single-objective machining process optimization models for the multipass turning machining process when compared with those of multi-objective machining process model yielded the minimum production cost and minimum production time as $\$ 5.775$ and 8.320 min respectively (and the corresponding production time and production cost as $12.996 \mathrm{~min}$ and $\$ 6.992$, respectively), while those of the multi-objective machining process optimization model were $\$ 5.841$ and $9.097 \mathrm{~min}$. Thus, the multi-objective machining process optimization model performed better than each of the single-objective model for the two criteria of minimum production cost and minimum production time respectively. The results also show that minimum production time model performs better than the minimum production cost model. For the example considered, the multi-objective model gave a lower production time of $30.0 \%$ than the corresponding production time obtained from the minimum production cost model, while it gave a lower production cost of $16.46 \%$ than the corresponding cost obtained by the minimum production time model.
\end{abstract}

Keywords: Turning process, Genetic Algorithms, minimum production cost, minimum production time, single-objective, multi-objective model

\section{INTRODUCTION}

The machining optimization problem being considered is a multi-objective problem.

The multi-objective methods provide two ways to solve multi- objective problems: combine them into a single objective using the weighted sum method or utility functions; and solve to obtain a set of nondominated Pareto optimal solutions, each solution providing a different tradeoff between the objectives under consideration. However, these single objective approaches have a limited value to fix the optimal cutting conditions, due to the complex nature of the machining processes, where several different and contradictory objectives must be simultaneously optimized.
Ahmad [1] stated that an optimal cutting condition for a machining operation is a multi-objective problem hence requires Multi-Criteria Decision-Making (MCDM) approaches. He used goal programming approach for the multi-objective optimization of the single-pass turning process, to find the optimal machining speed and feed rate values subject to a number of practical constraints including horsepower, permissible cutting speed, and permissible feed rate; with the objective functions of tool life and metal removal rate.

Cus et al [2] presented a multi-objective optimization of the end milling process by using neural network modeling and particle swamp optimization. They used the neural network to predict cutting forces during the machining operation and the particle swamp optimization to obtain the cutting speed and feed rate. 
Bouzakis et al [3] proposed, a multi-objective optimization procedure, based on Genetic Algorithms, to obtain the optimum cutting conditions (cutting depth, feed rate and cutting speed) in milling. Objective functions, like machining cost and machining time and several technological constrains were simultaneously taken into consideration. A Pareto ranking approach was used to determine the optimum cutting parameters. Milling simulation algorithms were taken into account in order to calculate chip thickness, cutting force, etc. An application example demonstrating the effectiveness of the proposed methodology was also presented.

Marler and Arora [4] surveyed the current continuous non-linear Multi-Objective Optimization (MOO) methods as well as the Genetic Algorithms. They also provided commentaries on the advantages and pitfalls of individual methods, the different classes of methods, and the field of MOO as a whole as well as the characteristics of the most significant methods. They found that no single approach was superior. Rather, the selection of a specific method depends on the type of information that is provided in the problem, the user's preferences, the solution requirements, and the availability of software.

Other multi-objective approaches have been reported in cutting parameters optimization $[5,6]$, but mainly use a priori techniques, where the decision maker combines the different objectives into a scalar cost function. This actually makes the multi-objective problem, single-objective prior to optimization [7].

Quiza-Sardinas et al [8], proposed a multiobjective optimization method, based on a posteriori techniques and using genetic algorithms, to obtain the optimal parameters in turning processes.

The widely used approach for solving multiobjective optimization problems is to transform a multiple objective (vector) problem into a singleobjective (scalar) problem. Among decision methods, weighted-sum aggregation of preferences is by far the most common, as it is a direct specification of important weights [9]. The weighted sum method transforms multiple objectives into an aggregated scalar objective function by multiplying each objective function by a weighting coefficient and summing up all contributors to look for the Pareto solution [10].

But the minimum production cost objective and the minimum production time objective are quite different by nature and values and could therefore not be aggregated as comparable objectives. Thus a normalization scheme is needed for the two objectives to be comparable criteria and their weights correctly applied to represent their relative importance $[11,12,13]$. The normalization not only transforms data to have comparable values but also transforms the problem to a maximization problem [9]. The weighted sum method requires multiplying each of the normalized objective functions by some weighting coefficients and summarizing them into a single objective function.

This work presents a method that determines weights for the objective functions without the articulation of preferences among the many criteria by the decision maker and without arbitrary choice of weights. This method is based on Genetic Algorithms, which maintains a population of encoded feasible solutions and guides the population towards the optimum solutions [14]; then after each search interval (i.e. generation), ideas or information about the performance (or possible solution) found by each member of the Genetic Algorithms population (i.e. the search team) can be used to determine such weights. The contribution of each member of the Genetic Algorithms population is reflected in the weight assigned to each objective function in the multiobjective optimization problem. This work is also concerns with evaluation of cost and time functions involved in multipass turning machining process, development of single-objective cost and time model as well as evaluation of the related practical constraints in order to determine optimum machining cutting parameters [15]. The model developed is then implemented in a Microsoft Visual Basic.Net environment to obtain optimum cutting machining parameters.

\section{METHODOLOGY}

\subsection{Development of the single-objective turning machining process optimization models}

Mathematical models have been developed for the multipass turning machining process for the unit production cost and time.

The unit production costs for the multi-pass turning Cut, is given by [16]:

$$
\begin{aligned}
\mathrm{C}_{\mathrm{ut}}= & \mathrm{k}_{\mathrm{O}}\left[\frac{\pi \mathrm{DL}}{1000 \mathrm{v}_{\mathrm{r}} \mathrm{f}_{\mathrm{r}}} \mathrm{N}_{\mathrm{rp}}+\frac{\pi \mathrm{DL}}{1000 \mathrm{v}_{\mathrm{s}} \mathrm{f}_{\mathrm{s}}}\right]+ \\
& +\mathrm{k}_{\mathrm{o}}\left[\mathrm{t}_{\mathrm{c}}+\left(\mathrm{h}_{1} \mathrm{~L}+\mathrm{h}_{2}\right)\left(\mathrm{N}_{\mathrm{rp}}+1\right)\right]+ \\
& +\mathrm{k}_{\mathrm{o}} \mathrm{t}_{\mathrm{e}}\left\{\frac{1}{\mathrm{~T}_{\mathrm{r}}}\left[\frac{\pi \mathrm{DL}}{1000 \mathrm{v}_{\mathrm{r}} \mathrm{f}_{\mathrm{r}}} \mathrm{N}_{\mathrm{rp}}\right]+\frac{1}{\mathrm{~T}_{\mathrm{s}}}\left[\frac{\pi \mathrm{DL}}{1000 \mathrm{v}_{\mathrm{s}} \mathrm{f}_{\mathrm{s}}}\right]\right\}+ \\
& +\mathrm{k}_{\mathrm{t}}\left\{\frac{1}{\mathrm{~T}_{\mathrm{r}}}\left[\frac{\pi \mathrm{DL}}{1000 \mathrm{v}_{\mathrm{r}} \mathrm{f}_{\mathrm{r}}} \mathrm{N}_{\mathrm{rp}}\right]+\frac{1}{\mathrm{~T}_{\mathrm{s}}}\left[\frac{\pi \mathrm{DL}}{1000 \mathrm{v}_{\mathrm{s}} \mathrm{f}_{\mathrm{s}}}\right]\right\} .
\end{aligned}
$$

The unit production time for the multi-pass turning $\mathrm{T}_{\mathrm{ut}}$, as given by [17] is given in eqn. (2) as:

$$
\begin{aligned}
& \mathrm{T}_{\mathrm{ut}}=\left[\frac{\pi \mathrm{DL}}{1000 \mathrm{v}_{\mathrm{r}} \mathrm{f}_{\mathrm{r}}} \mathrm{N}_{\mathrm{rp}}+\frac{\pi \mathrm{DL}}{1000 \mathrm{v}_{\mathrm{s}} \mathrm{f}_{\mathrm{s}}}\right] \\
& +\left[\mathrm{t}_{\mathrm{c}}+\left(\mathrm{h}_{1} \mathrm{~L}+\mathrm{h}_{2}\right)\left(\mathrm{N}_{\mathrm{rp}}+1\right)\right] \\
& +\mathrm{t}_{\mathrm{e}}\left\{\frac{1}{\mathrm{~T}_{\mathrm{r}}}\left[\frac{\pi \mathrm{DL}}{1000 \mathrm{v}_{\mathrm{r}} \mathrm{f}_{\mathrm{r}}} \mathrm{N}_{\mathrm{rp}}\right]+\frac{1}{\mathrm{~T}_{\mathrm{s}}}\left[\frac{\pi \mathrm{DL}}{1000 \mathrm{v}_{\mathrm{s}} \mathrm{f}_{\mathrm{s}}}\right]\right\} .
\end{aligned}
$$




\subsection{Development of the multi-objective} machining process optimization model

The developed multi-objective machining process optimization model can be written as:

$$
\begin{aligned}
\max . \Phi(\mathrm{v}, \mathrm{f}, \mathrm{d}) & =\left(\mathrm{C}_{\mathrm{ut}}(\mathrm{v}, \mathrm{f}, \mathrm{d}), \mathrm{T}_{\mathrm{ut}}(\mathrm{v}, \mathrm{f}, \mathrm{d})\right)^{\mathrm{T}} \\
& =\operatorname{Max} .\left(\mathrm{w}_{1} \mathrm{C}_{\mathrm{ut}}^{\mathrm{N}}+\mathrm{w}_{2} \mathrm{~T}_{\mathrm{ut}}^{\mathrm{N}}\right)=1
\end{aligned}
$$

subject to $g_{j}(v, f, d) \leq 0 j=1, J$

$\mathrm{h}_{\mathrm{k}}(\mathrm{v}, \mathrm{f}, \mathrm{d})=0 \mathrm{~K}=1, \mathrm{~K}$

$$
\begin{aligned}
& \mathrm{v}_{\mathrm{L}} \leq \mathrm{v} \leq \mathrm{v}_{\mathrm{U}} \\
& \mathrm{f}_{\mathrm{L}} \leq \mathrm{f} \leq \mathrm{f}_{\mathrm{U}} \\
& \mathrm{d}_{\mathrm{L}} \leq \mathrm{d} \leq \mathrm{d}_{\mathrm{U}} \\
& \mathrm{v}, \mathrm{f}, \mathrm{d} \geq 0 .
\end{aligned}
$$

The normalized production cost and time for the turning machining operations are given by eqns. (4) and (5) as:

$$
\begin{gathered}
C_{u, j}^{N}=\frac{C_{u}^{\max }-C_{u, j}}{C_{u}^{\max }-C_{u}^{\min }}, j=1,2, . ., n_{p}, \\
T_{u, j}^{N}=\frac{T_{u}^{\max }-T_{u, j}}{T_{u}^{\max }-T_{u}^{\min }}, j=1,2, . ., n_{p} .
\end{gathered}
$$

The corresponding weights, $w_{1}$ and $w_{2}$ as given by [18] are shown in eqns. (6) and (7) as:

$$
\begin{aligned}
& \mathrm{w}_{1}=\frac{\sum_{\mathrm{j}=1}^{\mathrm{n}_{\mathrm{p}}}\left(\frac{\mathrm{C}_{\mathrm{u}}^{\max }-C_{\mathrm{uj}}}{\mathrm{C}_{\mathrm{u}}^{\max }-C_{\mathrm{u}}^{\min }}\right)}{\sum_{\mathrm{j}=1}^{\mathrm{n}_{\mathrm{p}}}\left\{\left(\frac{\mathrm{C}_{\mathrm{u}}^{\max }-C_{u j}}{C_{u}^{\max }-C_{u}^{\min }}\right)+\left(\frac{\mathrm{T}_{\mathrm{u}}^{\max }-T_{\mathrm{uj}}}{\mathrm{T}_{\mathrm{u}}^{\max }-T_{2}^{\min }}\right)\right\}} \\
& =\frac{\sum_{j=1}^{n_{p}} C_{u, j}^{N}}{\sum_{j=1}^{n_{p}}\left(C_{u, j}^{N}+T_{u, j}^{N}\right)}, \\
& w_{2}=\frac{\sum_{j=1}^{n_{p}}\left(\frac{T_{u}^{\max }-T_{u j}}{T_{u}^{\max }-T_{u}^{\min }}\right)}{\sum_{j=1}^{n_{p}}\left\{\left(\frac{C_{u}^{\max }-C_{u j}}{C_{u}^{\max }-C_{u}^{\min }}\right)+\left(\frac{T_{u}^{\max }-T_{u j}}{T_{u}^{\max }-T_{2}^{\min }}\right)\right\}} \\
& =\frac{\sum_{j=1}^{n_{p}} T_{u, j}^{N}}{\sum_{j=1}^{n_{p}}\left(C_{u, j}^{N}+T_{u, j}^{N}\right)} .
\end{aligned}
$$

These models are optimized subject to the constraints specified by eqns. (8) - (31):

- bounds on cuttings peed:

$$
\begin{aligned}
& \text { roughing: } \mathrm{v}_{\mathrm{rL}} \leq \mathrm{v}_{\mathrm{r}}=\frac{\pi D N_{\mathrm{r}}}{1000} \leq \mathrm{v}_{\mathrm{rU}}, \\
& \text { finishing: } \mathrm{v}_{\mathrm{sL}} \leq \mathrm{v}_{\mathrm{s}}=\frac{\pi D N_{\mathrm{s}}}{1000} \leq \mathrm{v}_{\mathrm{sU}},
\end{aligned}
$$

- bounds on feed rate:

$$
\begin{aligned}
& \text { roughing: } f_{r L} \leq f_{r} \leq f_{r U}, \\
& \text { finishing: } f_{s L} \leq f_{s} \leq f_{s U},
\end{aligned}
$$

- bounds on depth of cut:

$$
\begin{aligned}
& \text { roughing: } \mathrm{d}_{\mathrm{rL}} \leq \mathrm{d}_{\mathrm{r}} \leq \mathrm{d}_{\mathrm{rU}}, \\
& \text { finishing: } \mathrm{d}_{\mathrm{sL}} \leq \mathrm{d}_{\mathrm{s}} \leq \mathrm{d}_{\mathrm{sU}},
\end{aligned}
$$

- tool Life constraint:

$$
\begin{gathered}
\text { roughing: } \mathrm{T}_{\mathrm{L}} \leq \mathrm{T}_{\mathrm{r}}=\frac{\mathrm{C}_{\mathrm{o}}}{\mathrm{v}_{\mathrm{r}}^{\alpha} \mathrm{f}_{\mathrm{r}}^{\beta} \mathrm{d}_{\mathrm{r}}^{\gamma}} \leq \mathrm{T}_{\mathrm{U}}, \\
\text { finishing: } \mathrm{T}_{\mathrm{L}} \leq \mathrm{T}_{\mathrm{s}}=\frac{\mathrm{c}_{\mathrm{o}}}{\mathrm{v}_{\mathrm{s}}^{\alpha} \mathrm{f}_{\mathrm{s}}^{\beta} \mathrm{d}_{\mathrm{s}}^{\gamma}} \leq \mathrm{T}_{\mathrm{U}},
\end{gathered}
$$

- cutting force constraint:

$$
\begin{aligned}
& \text { roughing: } F_{r}=k_{f} f_{r}^{\mu} d_{r}^{v} \leq F_{U}, \\
& \text { finishing: } F_{s}=k_{f} f_{s}^{\mu} d_{s}^{v} \leq F_{U},
\end{aligned}
$$

- cutting power constraint:

$$
\begin{aligned}
& \text { roughing: } P_{r}=\frac{k_{f} f_{r}^{\mu} d_{r}^{v} v_{r}}{60,000 \eta} \leq P_{U}, \\
& \text { finishing: } P_{s}=\frac{k_{f} f_{s}^{\mu} d_{s}^{v} v_{s}}{60,000 \eta} \leq P_{U},
\end{aligned}
$$

- chip-tool interface temperature constraint:

$$
\begin{aligned}
& \text { roughing: } \mathrm{Q}_{\mathrm{r}}=\mathrm{k}_{\mathrm{q}} \mathrm{v}_{\mathrm{r}}^{\tau} \mathrm{f}_{\mathrm{r}}^{\varphi} \mathrm{d}_{\mathrm{r}}^{\delta} \leq \mathrm{Q}_{\mathrm{U}}, \\
& \text { finishing: } \mathrm{Q}_{\mathrm{s}}=\mathrm{k}_{\mathrm{q}} \mathrm{v}_{\mathrm{s}}^{\tau} \mathrm{f}_{\mathrm{s}}^{\varphi} \mathrm{d}_{\mathrm{s}}^{\delta} \leq \mathrm{Q}_{\mathrm{U}},
\end{aligned}
$$

- dimensional accuracy constraint:

$$
\begin{aligned}
& \text { roughing: } \mathrm{DA}_{\mathrm{r}}=\mathrm{k}_{\mathrm{g}} \mathrm{v}_{\mathrm{r}}^{\chi} \mathrm{f}_{\mathrm{r}}^{\varsigma} \mathrm{d}_{\mathrm{r}}^{\psi} \leq \mathrm{DA}_{\mathrm{U}} \text {, } \\
& \text { finishing: } \mathrm{DA}_{\mathrm{s}}=\mathrm{k}_{\mathrm{g}} \mathrm{v}_{\mathrm{s}}^{\chi} \mathrm{f}_{\mathrm{s}}^{\varsigma} \mathrm{d}_{\mathrm{s}}^{\psi} \leq \mathrm{DA}_{\mathrm{U}},
\end{aligned}
$$

- stable cutting region constraint:

$$
\begin{aligned}
& \text { roughing: } \mathrm{SC}_{\mathrm{r}}=\mathrm{v}_{\mathrm{r}}^{\lambda} \mathrm{f}_{\mathrm{r}} \mathrm{d}_{\mathrm{r}}^{\mathrm{v}} \geq \mathrm{SC}, \\
& \text { finishing: } \mathrm{SC}_{\mathrm{s}}=\mathrm{v}_{\mathrm{s}}^{\lambda} \mathrm{f}_{\mathrm{s}} \mathrm{d}_{\mathrm{s}}^{\mathrm{v}} \geq \mathrm{SC},
\end{aligned}
$$

- surface finish constraint:

$$
\text { finishing: } \mathrm{SR}_{\mathrm{s}}=\frac{\mathrm{f}_{\mathrm{s}}^{2}}{8 \mathrm{R}} \leq \mathrm{SR}_{\mathrm{U}} \text {, }
$$

- miscellaneous constraints:

finishing cutting speed: $\mathrm{v}_{\mathrm{s}} \geq 1.2 \mathrm{v}_{\mathrm{r}}$,

finishing feed rate: $f_{s} \leq 0.6 f_{r}$,

finishing depth of cut: $d_{s} \leq 0.5 d_{r}$,

Total depth of cut constraint: $\mathrm{d}_{\mathrm{s}}=\mathrm{d}_{\mathrm{t}}-\mathrm{n}$,

- bounds on number of rough cuts:

$$
\mathrm{N}_{\mathrm{L}}=\frac{\mathrm{d}_{\mathrm{t}}-\mathrm{d}_{\mathrm{sU}}}{\mathrm{d}_{\mathrm{rU}}} \leq \mathrm{n} \leq \mathrm{N}_{\mathrm{U}}=\frac{\mathrm{d}_{\mathrm{t}}-\mathrm{d}_{\mathrm{sL}}}{\mathrm{d}_{\mathrm{rL}}} .
$$




\subsection{Steps in the multi-objective Genetic Algorithm methodology}

The multi-objective Genetic Algorithms methodology was implemented by applying the weighted method developed by [18], given as Figs 1-2.

// Set $i_{\max }=$ Max. No. of generations

$i=1:$ //Initialize generations

For $j=1$ To $n_{q}: / / n_{q}=20$ GA population size

For $k=1$ To $n_{r}: / /$

// Generate initial random population

// of $n_{q}$ chromosomes (suitable solutions

// for the problem)

//Evaluate the fitness $f_{i j k}(x)=f(x)$ of each

// chromosome $x$ in the population

Next $k$

Next $j$

1 For $j=1$ To $n_{q}$

Sum $=0$

For $k=1$ To $n_{r}$

$$
\begin{aligned}
& f_{i j k}^{\text {norm }}=\frac{\left(f_{i j k}^{\max }-f_{i j k}\right)}{\left(f_{i j k}^{\max }-f_{i j k}^{\min }\right)} \\
& \operatorname{Sum}(i j k)=\operatorname{Sum}+f_{i j k}^{\text {norm }}(x) \\
& \text { Sum }=\operatorname{Sum}(i j k) \\
& \text { Next } k
\end{aligned}
$$

\section{Next $j$}

SumTotal $=0$

For $k=1$ To $n_{r}$

SumTotal $=$ SumTotal + Sum $(i j k)$

Next $k$

For $k=1$ To $n_{r}$

$$
w(i j k)=\frac{\operatorname{Sum}(i j k)}{\text { SumTotal }}
$$

Next $k$

$$
\begin{aligned}
& \text { For } j=1 \text { To }_{q} \\
& \text { Cum }=0 \\
& \text { For } k=1 \text { To } n_{r} \\
& \quad F_{i j k}^{N}(x)=w(i j k) * f_{i j k}^{n o r m}(x) \\
& \quad C_{i j k}^{N}(x)=C u m+F_{i j k}^{N}(x) \\
& \quad \text { Cum }=C_{i j k}^{N}(x) \\
& \quad \text { If } C_{i j k}^{N}(x)=f_{i j k}^{\text {norm }}(x)=1 \text { Then GoTo } 2
\end{aligned}
$$

Next $k$

\section{Next $j$}

//Carry out GA procedure of creation of new populations as thus:

//Create a new population by repeating following steps until the new population is complete

Fig. 1. Genetic Algorithm methodology 1/2 a. [Selection] Select two parent chromosomes from a population according to their fitness (the better fitness, the bigger chance to be selected)

b. [Crossover] With a crossover probability cross over the parents to form new offspring (children). If no crossover was performed, offspring is the exact copy of parents.

c. [Mutation] With a mutation probability mutate new offspring at each locus (position in chromosome).

d. [Accepting] Place new offspring in the new population

// Evaluate the new generated population for a further run of the algorithm

For $j=1$ To $n_{q}: / / n_{q}=20$ GA population size

For $k=1$ To $n_{r}$ :

//Evaluate the fitness $f_{i j k}(x)=f(x)$ of

/leach chromosome $x$ in the population

Next $k$

Next $j$

$i=i+1$

GoTo 1

2 /Display optimum results: Optimum decision variables; optimum objective functions

// values; Optimum multi-objective function value; and no. of GA generations

End

Fig. 2. Genetic Algorithm methodology $2 / 2$

\subsection{Implementation}

The elements of the proposed models developed using Genetic Algorithm have been implemented in the software developed in Microsoft Visual Basic.Net environment and run on a Pentium $4 \mathrm{PC}$ with $3.0 \mathrm{GHz}$ Intel Processor and 2 GB of RAM. The values set for different parameters of the genetic algorithm are shown in Table 1.

Tab. 1. Genetic Algorithms parameters

\begin{tabular}{ll}
\hline Population size & 20 \\
\hline $\begin{array}{l}\text { Number of population } \\
\text { generation }\end{array}$ & 50 \\
\hline Length chromosomes & 49 \\
\hline Selection operator & Roulette Wheel \\
\hline Crossover operator & One-point operator \\
\hline Crossover probability & 0.80 \\
\hline Mutation probability & 0.01 \\
\hline Fitness measure & Multi-objective model \\
\hline
\end{tabular}




\subsection{Illustrative example}

An illustrative example has been adopted from $[15,16]$ to demonstrate the performance of the proposed models. Table 2 shows the data of the illustrative example.

Tab. 2. Data of Chen and Tseng [19] and Onwubolu and Kumalu [16]

\begin{tabular}{ccc}
\hline$v_{r L}=90 \mathrm{~m} / \mathrm{min}$ & $v_{r U}=500 \mathrm{~m} / \mathrm{min}$ & $v_{s L}=90 \mathrm{~m} / \mathrm{min}$ \\
\hline$v_{s U}=500 \mathrm{~m} / \mathrm{min}$ & $f_{r L}=0.1 \mathrm{~mm} / \mathrm{rev}$ & $\alpha=5$ \\
\hline$\tau=0.40$ & $f_{s L}=0.1 \mathrm{~mm} / \mathrm{rev}$ & $f_{s U}=1.0 \mathrm{~mm} / \mathrm{rev}$ \\
\hline$d_{r L}=1.0 \mathrm{~mm}$ & $d_{r U}=3.0 \mathrm{~mm}$ & $d_{s L}=1.0 \mathrm{~mm}$ \\
\hline$v=0.95$ & $\mu=0.75$ & $K_{o}=0.5 \$ / \mathrm{min}$ \\
\hline$K_{t}=2.5 \$ / \mathrm{min}$ & $T_{L}=25 \mathrm{~min}$ & $T_{U}=45 \mathrm{~min}$ \\
\hline$S R_{U}=10 \mu \mathrm{m}$ & $\varsigma=0.9709$ & $Q_{U}=1000^{\circ} \mathrm{C}$ \\
\hline$h_{2}=0.3 \mathrm{~min}$ & $F_{U}=5.0 \mathrm{kgf}$ & $P_{U}=200 \mathrm{~kW}$ \\
\hline$R=1.2 \mathrm{~mm}$ & $\eta=0.85$ & $C=140$ \\
\hline$K_{f}=108$ & $K_{q}=132$ & $d_{s U}=3.0 \mathrm{~mm}$ \\
\hline$\Phi=0.2$ & $h_{l}=7 \times 10^{-4} \mathrm{~min} / \mathrm{mm}$ & $T_{e}=1.5 \mathrm{~min} / \mathrm{edge}$ \\
\hline$\delta=0.105$ & $f_{r U}=1.0 \mathrm{~mm} / \mathrm{rev}$ & $\beta=1.75$ \\
\hline$C_{o}=6 \times 10^{11}$ & $k_{r}=100.66$ & $X=-0.2848$ \\
\hline$T c=0.75$ & $\psi=0.4905$ & $v=-1$ \\
\hline$\gamma=0.75$ & $\lambda=2$ & $\mathrm{piece}$
\end{tabular}

2.6. Illustration of the multi-objective model using data of Amiolemhen and Ibhadode [15]

An illustrative example has been adopted from [15] to demonstrate the performance of the the multiobjective model for multi-pass turning operation.

The cutting parameters of cutting speed, feed rate and depth of cut are shown in columns 2, 3 and 4 of Table 3, while the objective functions values of the minimum production cost and minimum production time are shown in columns 5 and 6 of Table 3.

The normalized values of the minimum production cost, minimum production time and the multiobjective models are shown in columns 7, 8 and 9 of Table 3.
The normalized values of the Multiobjective model, shown in column 9; were obtained by summation of each normalized single objective model multiply by its respective estimated weight, $w^{*}$. And, these weights were determined from eqns. (6) and (7) as thus:

$$
\begin{aligned}
& \mathrm{w}_{1}=\frac{\sum_{\mathrm{j}=1}^{\mathrm{n}_{\mathrm{p}}}\left(\frac{\mathrm{C}_{\mathrm{u}}^{\max }-\mathrm{C}_{\mathrm{uj}}}{\mathrm{C}_{\mathrm{u}}^{\max }-\mathrm{C}_{\mathrm{u}}^{\min }}\right)}{\sum_{\mathrm{j}=1}^{\mathrm{n}_{\mathrm{p}}}\left\{\left(\frac{\mathrm{C}_{\mathrm{u}}^{\max }-\mathrm{C}_{\mathrm{uj}}}{\mathrm{C}_{\mathrm{u}}^{\max }-C_{\mathrm{u}}^{\min }}\right)+\left(\frac{\mathrm{T}_{\mathrm{u}}^{\max }-\mathrm{T}_{\mathrm{uj}}}{\mathrm{T}_{\mathrm{u}}^{\max }-\mathrm{T}_{2}^{\min }}\right)\right\}} \\
& =\frac{\sum_{\mathrm{j}=1}^{\mathrm{n}_{\mathrm{p}}} \mathrm{C}_{\mathrm{u}, \mathrm{j}}^{\mathrm{N}}}{\sum_{\mathrm{j}=1}^{\mathrm{n}_{\mathrm{p}}}\left(\mathrm{C}_{\mathrm{u}, \mathrm{j}}^{\mathrm{N}}+\mathrm{T}_{\mathrm{u}, \mathrm{j}}^{\mathrm{N}}\right)}=\frac{14.085}{14.085+14.682}=0.490, \\
& \mathrm{w}_{2}=\frac{\sum_{\mathrm{j}=1}^{\mathrm{n}_{\mathrm{p}}}\left(\frac{\mathrm{T}_{\mathrm{u}}^{\max }-\mathrm{T}_{\mathrm{uj}}}{\mathrm{T}_{\mathrm{u}}^{\max }-\mathrm{T}_{\mathrm{u}}^{\min }}\right)}{\sum_{\mathrm{j}=1}^{\mathrm{n}_{\mathrm{p}}}\left\{\left(\frac{\mathrm{C}_{\mathrm{u}}^{\max }-\mathrm{C}_{\mathrm{uj}}}{\mathrm{C}_{\mathrm{u}}^{\max }-C_{\mathrm{u}}^{\min }}\right)+\left(\frac{\mathrm{T}_{\mathrm{u}}^{\max }-\mathrm{T}_{\mathrm{uj}}}{\mathrm{T}_{\mathrm{u}}^{\max }-\mathrm{T}_{2}^{\min }}\right)\right\}} \\
& =\frac{\sum_{\mathrm{j}=1}^{\mathrm{n}_{\mathrm{p}}} \mathrm{T}_{\mathrm{u}, \mathrm{j}}^{\mathrm{N}}}{\sum_{\mathrm{j}=1}^{\mathrm{n}_{\mathrm{p}}}\left(\mathrm{C}_{\mathrm{u}, \mathrm{j}}^{\mathrm{N}}+\mathrm{T}_{\mathrm{u}, \mathrm{j}}^{\mathrm{N}}\right)}=\frac{14.682}{14.085+14.682}=0.510 .
\end{aligned}
$$

The normalization processes were computed using eqns. (4) and (5) as follows:

$$
\begin{aligned}
& \mathrm{C}_{\mathrm{u}, \mathrm{j}}^{\mathrm{N}}=\frac{\mathrm{C}_{\mathrm{u}}^{\max }-\mathrm{C}_{\mathrm{u}, 1}}{\mathrm{C}_{\mathrm{u}}^{\max }-\mathrm{C}_{\mathrm{u}}^{\min }}=\frac{83.75-20.13}{83.75-14.95}=0.872
\end{aligned}
$$

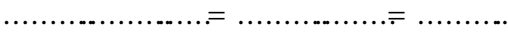

$$
\begin{aligned}
& \mathrm{C}_{\mathrm{u}, 20}^{\mathrm{N}}=\frac{\mathrm{C}_{\mathrm{u}}^{\max }-\mathrm{C}_{\mathrm{u}, 20}}{\mathrm{C}_{\mathrm{u}}^{\max }-\mathrm{C}_{\mathrm{u}}^{\min }}=\frac{83.75-15.62}{83.75-14.95}=0.998, \\
& \mathrm{~T}_{\mathrm{u}, 1}^{\mathrm{N}}=\frac{\mathrm{T}_{\mathrm{u}}^{\max }-\mathrm{T}_{\mathrm{u}, 1}}{\mathrm{~T}_{\mathrm{u}}^{\max }-\mathrm{T}_{\mathrm{u}}^{\min }}=\frac{167.34-38.00}{167.34-19.01}=0.923
\end{aligned}
$$

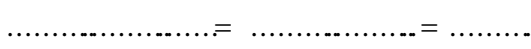

$$
\begin{aligned}
& \mathrm{T}_{\mathrm{u}, 20}^{\mathrm{N}}=\frac{\mathrm{T}_{\mathrm{u}}^{\max }-\mathrm{T}_{\mathrm{u}, 20}}{\mathrm{~T}_{\mathrm{u}}^{\max }-\mathrm{T}_{\mathrm{u}}^{\min }}=\frac{167.34-19.33}{167.34-19.01}=0.989 .
\end{aligned}
$$

The multi-objective model values were computed using eqn. (3) as follows:

$\left(w_{1} C_{u 1}^{N}+w_{2} T_{u 1}^{N}\right)=0.490 \times 0.872+0.510 \times 0.923=0.898$

$\left(\mathrm{w}_{1} \mathrm{C}_{\mathrm{u} 20}^{\mathrm{N}}+\mathrm{w}_{2} \mathrm{~T}_{\mathrm{u} 20}^{\mathrm{N}}\right)=0.490 \times 0.998+0.510 \times 0.989=0.993$. 
Tab. 3. Data of Amiolemhen and Ibhadode [15]

\begin{tabular}{|c|c|c|c|c|c|c|c|c|}
\hline $\mathrm{S} / \mathrm{N}$ & $\begin{array}{l}\text { Cutting } \\
\text { speed ,v } \\
(\mathrm{m} / \mathrm{min})\end{array}$ & $\begin{array}{l}\text { Feed rate, } f \\
(\mathrm{~mm} / \mathrm{rev})\end{array}$ & $\begin{array}{l}\text { Depth of cut, } \\
d(\mathrm{~mm})\end{array}$ & $\begin{array}{l}\text { Min. prod. } \\
\text { time, } T u \\
\text { (min/piece) }\end{array}$ & $\begin{array}{l}\text { Min. prod. } \\
\text { cost, } C u \\
(\$ / \text { piece })\end{array}$ & $\begin{array}{l}\text { Norm. min. } \\
\text { prod. time, } \\
\quad T u N\end{array}$ & $\begin{array}{l}\text { Norm. min. } \\
\text { prod. cost, } \\
\quad C u N\end{array}$ & Multi- obj. \\
\hline 1 & 157.770 & 0.249 & 1.331 & 38.000 & 20.13033 & 0.923 & 0.872 & 0.898 \\
\hline 2 & 199.365 & 0.340 & 1.533 & 22.653 & 14.84944 & 1.000 & 0.975 & 0.988 \\
\hline 3 & 209.031 & 0.361 & 1.581 & 20.945 & 14.89608 & 0.999 & 0.987 & 0.993 \\
\hline 4 & 149.362 & 0.230 & 1.290 & 43.695 & 22.71106 & 0.886 & 0.834 & 0.860 \\
\hline 5 & 158.331 & 0.250 & 1.333 & 37.668 & 19.98419 & 0.925 & 0.874 & 0.900 \\
\hline 6 & 149.792 & 0.231 & 1.292 & 43.477 & 22.61254 & 0.887 & 0.835 & 0.862 \\
\hline 7 & 93.737 & 0.108 & 1.018 & 167.343 & 83.75185 & 0.000 & 0.000 & 0.000 \\
\hline 8 & 145.458 & 0.222 & 1.271 & 46.823 & 24.11693 & 0.865 & 0.813 & 0.839 \\
\hline 9 & 154.471 & 0.242 & 1.314 & 40.083 & 21.06037 & 0.910 & 0.858 & 0.884 \\
\hline 10 & 149.672 & 0.231 & 1.291 & 43.466 & 22.60522 & 0.887 & 0.835 & 0.862 \\
\hline 11 & 106.529 & 0.136 & 1.081 & 112.542 & 56.42846 & 0.397 & 0.369 & 0.383 \\
\hline 12 & 226.139 & 0.399 & 1.664 & 19.013 & 15.95387 & 0.984 & 1.000 & 0.992 \\
\hline 13 & 119.894 & 0.166 & 1.145 & 79.664 & 40.12018 & 0.633 & 0.591 & 0.613 \\
\hline 14 & 149.774 & 0.231 & 1.292 & 43.390 & 22.57031 & 0.888 & 0.836 & 0.862 \\
\hline 15 & 218.626 & 0.382 & 1.627 & 19.705 & 15.33786 & 0.993 & 0.995 & 0.994 \\
\hline 16 & 98.2160 & 0.118 & 1.040 & 144.239 & 72.22248 & 0.167 & 0.156 & 0.162 \\
\hline 17 & 116.554 & 0.158 & 1.130 & 86.436 & 43.46744 & 0.585 & 0.545 & 0.565 \\
\hline 18 & 104.948 & 0.133 & 1.073 & 117.760 & 59.02573 & 0.359 & 0.334 & 0.347 \\
\hline 19 & 106.948 & 0.137 & 1.083 & 111.342 & 55.83138 & 0.405 & 0.378 & 0.392 \\
\hline 20 & 222.380 & 0.391 & 1.646 & 19.330 & 15.61603 & 0.989 & 0.998 & 0.993 \\
\hline
\end{tabular}

\section{RESULTS AND DISCUSSION}

\subsection{Figures and Tables}

Figures 3 and 4 show the plot of the fractional fitness superimposed on the plots for the minimum production time, $\mathrm{Tu}$ and minimum production cost, $\mathrm{Cu}$. The figure also shows that there seems to be no immediate discernable pattern of variation of fractional fitness with number of generations. This is due to the complex operations that take place in the implementation of the GAs solution that give rise to the fractional fitness. However, the spikes appearing at the 2nd, 18th, 26th, 28th, 40th, 42nd and 50th generations may be due to the resetting of the GAs operators at those generations. However, changes observed between the 1st and 9th, 16th and 21st, 21st and 32nd GA generations are due to the setting of the Gas operators of crossover and mutation at those generations.

Figure 5 shows the plots of the normalized combined criteria superimposed on the plots for minimum production time $\mathrm{Tu}$ and minimum production cost $\mathrm{Cu}$ against number of generations. The figure shows that from the 1 st to the 9th generations, there are sharp reductions in production time and production cost of $47.4 \%$ and $53.8 \%$ respectively along with instability in their variations within this region. From the 10th to the 33rd generations, further reductions are shown with some instability in variations observed more for the production cost 
curve. Thereafter, the curves converge to constant values of $9.1 \mathrm{~min} /$ piece and $\$ 5.8 /$ piece for the minimum production time and minimum production cost respectively.

The figure also shows that there are variations of the combined criteria curve at generations where the minimum production time and minimum production cost are varying. At generations where minimum production time and minimum production cost are constant, the combined criteria curve has constant value of 1 . This is a consequence of the definition of the multi-objective model given by eqn. (3).

Figure 6 shows the variations of the normalized values of the minimum production time, $\mathrm{Tu}$, minimum production cost, $\mathrm{Cu}$ and the combined criteria against number of generations. The figure shows that the combined criteria plot is a weighted mean of the normalized minimum production time and normalized minimum production cost as given by eqn. (3).

Figure 7 shows the plot of minimum production cost and minimum production time against the number of GA generations for the turning machining operation. The figure shows that the production cost drops rapidly from $\$ 15.338 /$ piece from the 1 st generation to $9.328 /$ piece at the 2 nd generation, giving a cost slope of $\$ 6.010 /$ generation. From the 2 nd generation to the 3 rd generation the production cost drops from $\$ 9.328 /$ piece to $\$ 8.615 /$ piece giving a cost slope decrease of $\$ 0.0 .713 /$ generation. From the $3 \mathrm{rd}$ generation to the 4 th generation the production cost remains constant. From the 4th generation to the 5th generation the production cost increases from $\$ 8.615 /$ piece to $\$ 10.081 /$ piece giving a cost slope rise of $\$ 1.466 /$ generation. From the 5 th generation to the 6 th generation the production cost remains constant. From the 6th generation to the 7 th generation the production cost drops from $\$ 10.081 /$ piece to $\$ 7.630 /$ piece, giving a cost slope of $\$ 2.451 /$ generation. From the 7 th generation to the 8 th generation the production cost drops from $\$ 7.630 /$ piece to $\$ 7.483 /$ piece, giving a cost slope of $\$ 0.147 /$ generation. From the 8th generation to the 9th generation the production cost drops from \$7.483/piece to $\$ 7.093 /$ piece, giving a cost slope of $\$ 0.370 /$ generation. From the 9th generation to the 16th generation the production time remains constant. From the 16th generation to the 17 th generation, the production time increase from $\$ 7.093 /$ piece to $\$ 8.013 /$ piece, giving a time slope rise of $\$ 0.920 /$ generation. From the 17 th generation to the 20th generation the production time remains constant. From the 20th generation to the $21 \mathrm{st}$ generation the production cost drops from $\$ 8.013 /$ piece to $\$ 7.062 /$ piece, giving a cost slope of $\$ 0.951 /$ generation. From the 21st generation to the 22nd generation the production time remains constant. From the 22nd generation to the 23rd generation the production cost increases from $\$ 7.062 /$ piece to
$\$ 7.136 /$ piece, giving a cost slope of $\$ 0.074 /$ generation. From the 23rd generation to the 32 nd generation the production time remains constant. From the 32nd generation to the 33rd generation the production cost drops from $\$ 7.136 /$ piece to $\$ 5.841 /$ piece, giving a cost slope of $\$ 1.265 /$ generation. Thereafter, the production cost remains constant till the 50th generation. This is a cost slope of about 190 times less than that between the 1 st and the 7 th generations. This goes to show how effective the GAs solution technique is in converging quickly to the optimum value.

The figure also shows that the production time drops rapidly from $19.705 \mathrm{~min} /$ piece from the $1 \mathrm{st}$ generation to $14.916 \mathrm{~min} /$ piece at the 2 nd generation, giving a time slope of $4.789 \mathrm{~min} /$ generation. From the 2nd generation to the $3 \mathrm{rd}$ generation the production time increases from $14.916 \mathrm{~min} /$ piece to 15.893 $\mathrm{min} /$ piece giving a time slope increase of 0.977 $\mathrm{min} /$ generation. From the $3 \mathrm{rd}$ generation to the 4 th generation the production time remains constant. From the 4 th generation to the 5 th generation the production time drops from $15.893 \mathrm{~min} /$ piece to $14.338 \mathrm{~min} /$ piece giving a time slope drop of $1.555 \mathrm{~min} /$ generation. From the 5th generation to the 6th generation the production time remains constant. From the 6th generation to the 8 th generation the production time had average drops of $1.68 \mathrm{~min} /$ generation. From the 8 th generation to the 16th generation the production time remains constant. From the 16th generation to the 17th generation the production time drops from 10.369 $\mathrm{min} /$ piece to $9.780 \mathrm{~min} /$ piece giving a time slope drop of $0.589 \mathrm{~min} /$ generation. From the 17 th generation to the 20th generation the production time remains constant. From the 20th generation to the 33rd generation the production time drops from 9.780 $\mathrm{min} /$ piece to $9.097 \mathrm{~min} /$ piece giving a time slope drop of $0.683 \mathrm{~min} /$ generation. Thereafter, the production time remains constant till the 50th generation giving a time slope of $0.04 /$ generation. This is a time slope of about 180 times less than that between the 1st and the 7 th generations. This goes to show how effective the GAs solution technique is in converging quickly to the optimum value.

Figure 8 shows the variation of the weights of the normalized criteria over the 50 population generations. The figure shows that the values of weights are mirror images of each other about the mean weight of 0.5 .

Figure 9 shows the optimum results obtained from the three models for the turning machining operation. The figure shows that using the minimum production cost model while giving an optimum production cost of $\$ 5.775$ predicts a much higher production time of 12.996 min over the optimum production time of 8.320 min predicted by the minimum production time model; that is $56.20 \%$ greater. On the other hand, the minimum production time model giving an optimum production time of 8.32 min predicts a slightly more 
production cost of $\$ 6.992$ over the optimum production cost of $\$ 5.775$ predicted by the minimum production cost model, that is, $21.07 \%$ greater. These results suggest that the minimum production time model seems to perform better than the minimum production cost model. This may be true for most cases in the real world of work. Hence, we find that the minimum production time model is adopted when productive efficiency is desired. Whereas, the minimum production cost model is adopted when there is ample time for production. However, in highperforming organizations which all organizations strive to be, time is of utmost importance; and it will be counter-productive to spend more time on a job which can be done in less time for the same quality.

The multi-objective model gave the production cost of $\$ 5.841 /$ piece and the production time of 9.097 min/piece. The multi-objective model gives a higher production cost of $1.14 \%$ than the minimum production cost model while it also gives a higher production time of $9.34 \%$ than the minimum production time model. These higher results from the multi-objective model than the single-objective models are expected because the multi-objective model is a combination of the two conflicting singleobjective models and therefore gives compromise results (or tradeoff results). However, the figure shows that the multi-objective model gives a lower production time of $43.9 \%$ than the corresponding production time obtained from the minimum production cost model while it also gives a lower production cost of $19.7 \%$ than the corresponding production cost obtained by the minimum production time model.

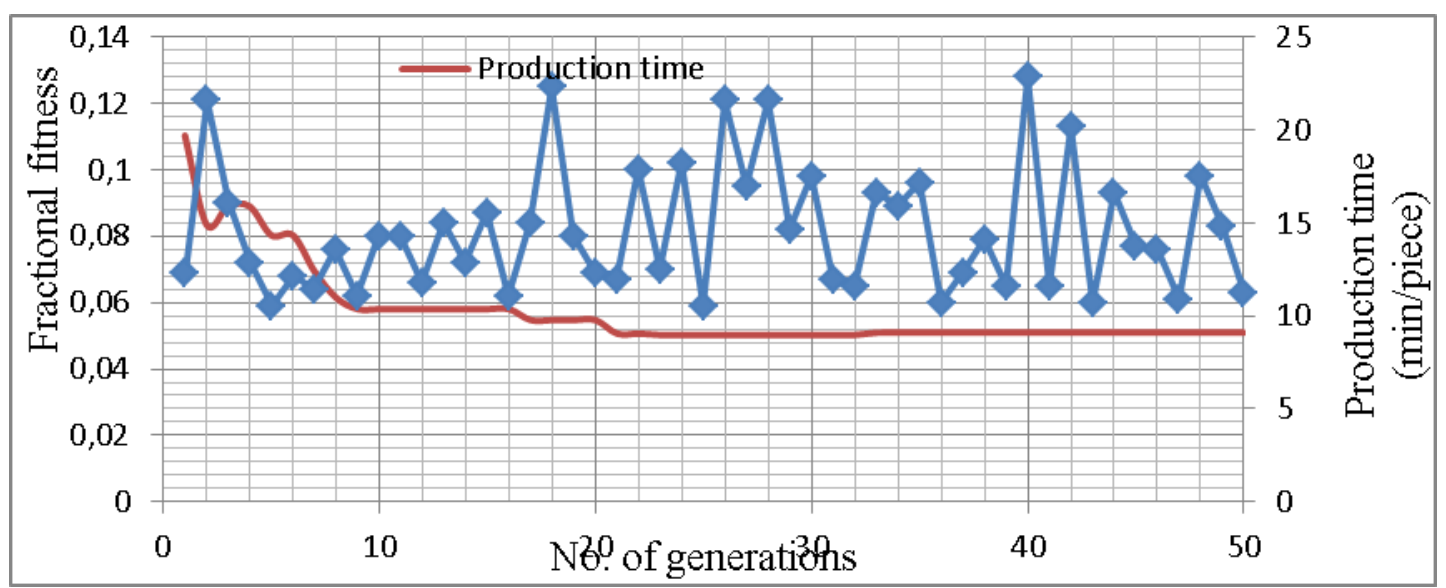

Fig. 3. Plots of fractional fitness and minimum production time against number of generations

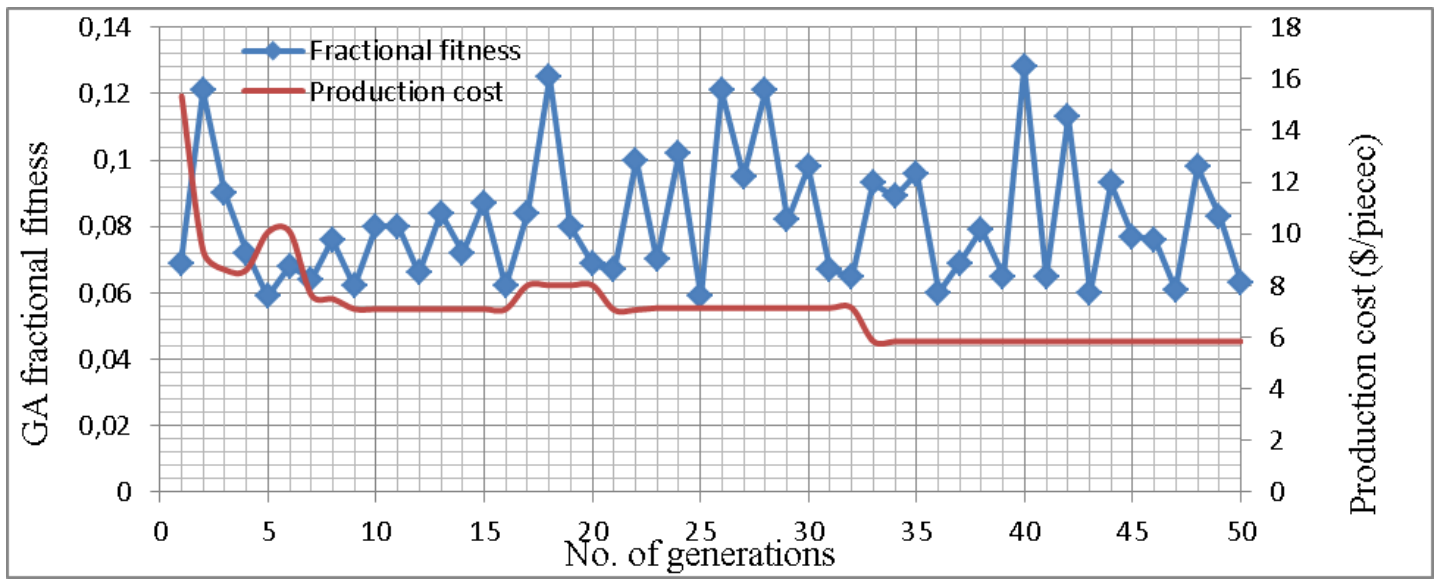

Fig. 4. Plots of fractional fitness and minimum production cost against number of generations 


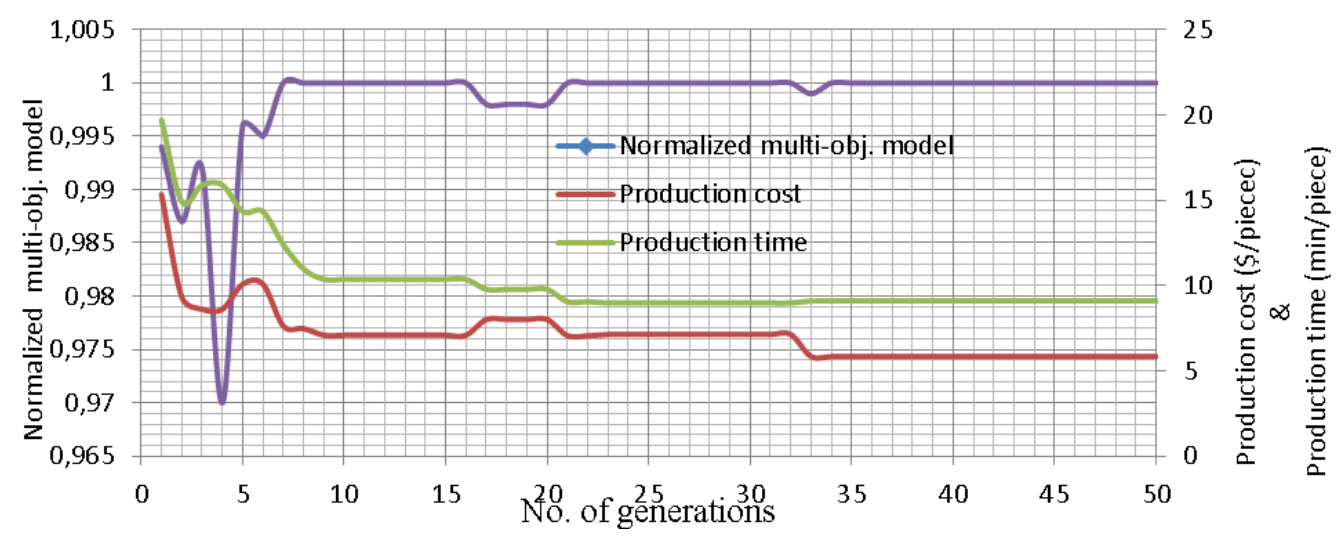

Fig. 5. Plots of normalized combined criteria, minimum production time and minimum production cost against number of generations

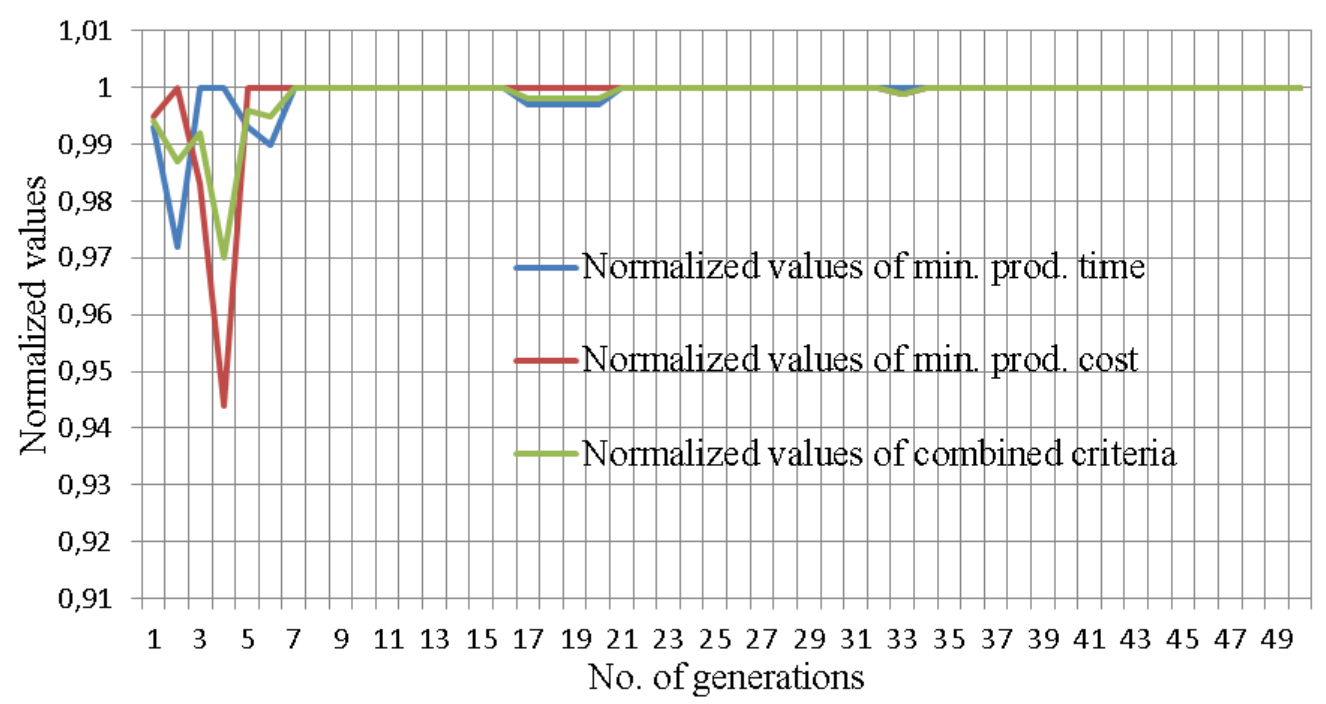

Fig. 6. Plots of normalized values of minimum production time, minimum production cost and the combined criteria against number of generations

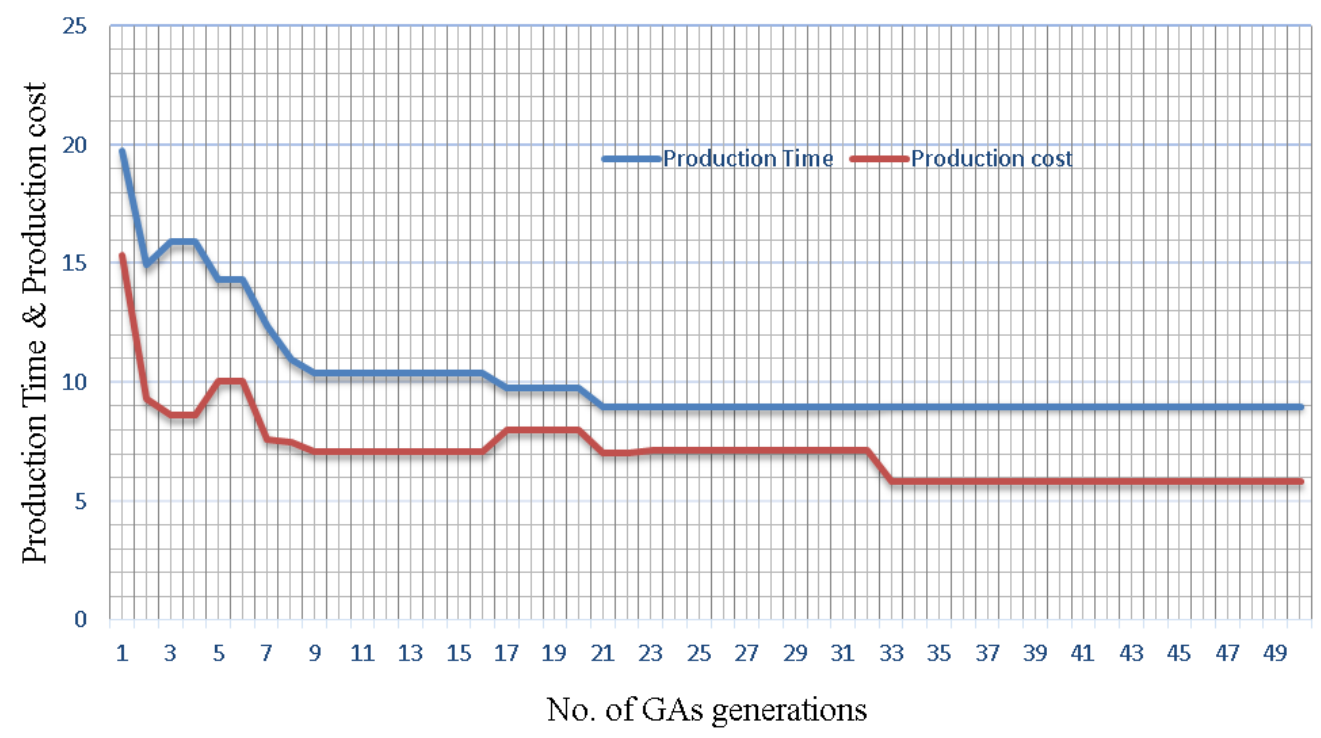

Fig. 7. Plots of minimum production time and minimum production cost against number of generations 


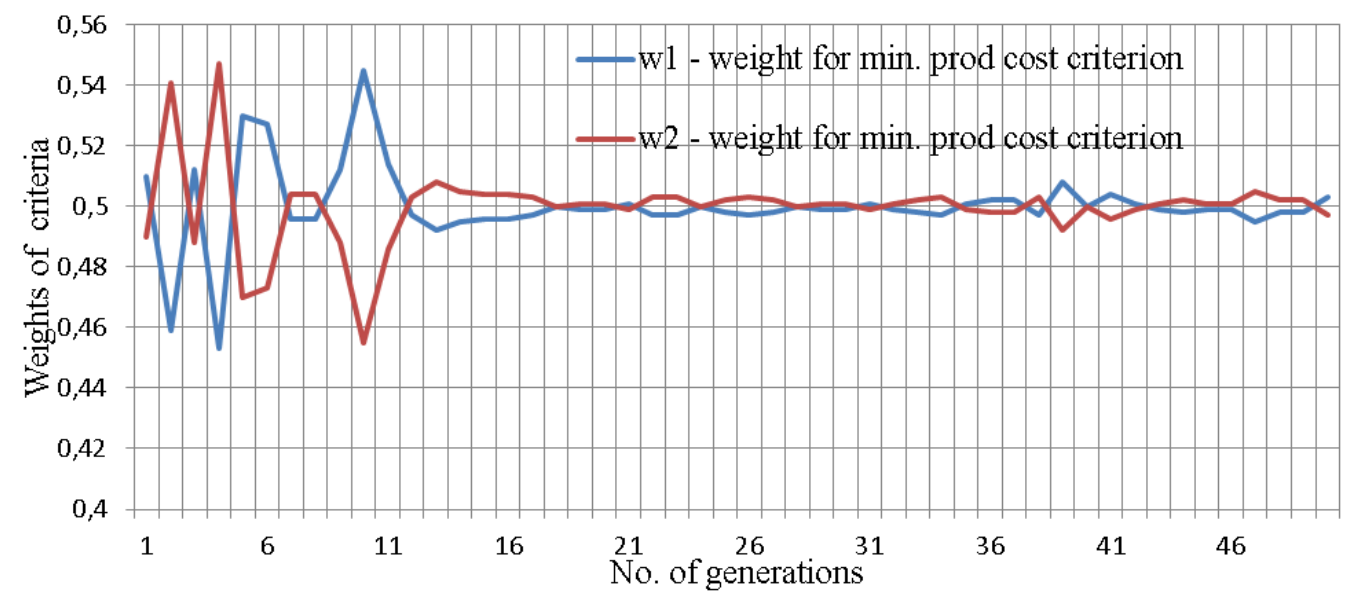

Fig. 8. Plots of weights of minimum production time and minimum production cost against number of generations

\section{Comparison of results for the three models}

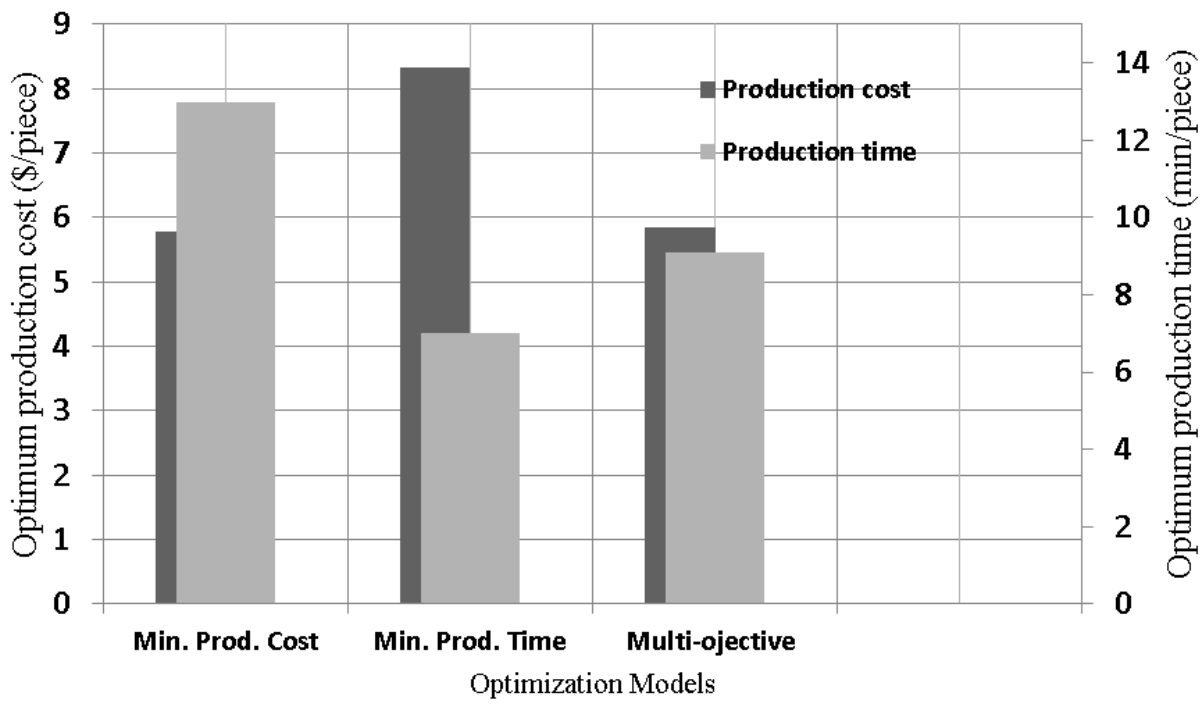

Fig. 9. Comparison of results of the three models

\section{CONCLUSIONS}

The results of the single-objective machining process optimization models for the multipass turning machining process when compared with those of multi-objective machining process model yielded the minimum production cost and minimum production time as $\$ 5.775$ and $8.320 \mathrm{~min}$ respectively (and the corresponding production time and production cost as $12.996 \mathrm{~min}$ and $\$ 6.992$, respectively), while those of the multi-objective machining process optimization model were $\$ 5.841$ and $9.097 \mathrm{~min}$. Thus, the multiobjective machining process optimization model performed better than each of the single-objective model for the two criteria of minimum production cost and minimum production time respectively. From the analysis of results, it appears that the minimum production time model performs better than the minimum production cost model. Thus, for real shop floor conditions in which time is of essence, it is recommended that the minimum production time model be used. Moreover, the analysis of results further shows that the machining process optimization problem is actually a multi-objective optimization problem with several constraints and two conflicting objective functions of minimum production cost and minimum production time models. Due to the ability of the multi-objective criteria model to combine the effects of two conflicting objectives, the model is able to predict better performance indices than the singleobjective models of cost and time. Thus, for the example considered, the multi-objective model gave a lower production time of $30.0 \%$ than the corresponding production time obtained from the minim,um production cost model, while it gave a lower production cost of $16.46 \%$ than the 
corresponding cost obtained by the minimum $d_{t}$ production time model.

\section{Nomenclature}

\section{Symbols}

C conservative tool-life constant, dependent on cutting tool material/work-piece combination

$C f_{i} \quad$ cumulative fitness of a population

$\mathrm{C}_{\mathrm{it}} \quad$ machine idle cost due to loading and unloading operations and tool idle motion

$C_{m t} \quad$ cutting cost by actual time in cut for turning (\$/piece)

$C_{u}^{\text {Norm }}$ normalized minimum production cost

$C_{o} \quad$ tool-life constant, dependent on cutting tool material/work-piece combination

$C_{r t} \quad$ tool replacement cost for turning (\$/piece)

$C_{t t} \quad$ tool cost for turning (\$/piece)

$C_{u t} \quad$ unit production cost except material cost for (\$/piece)

$D \quad$ diameter of work-piece (mm)

$D A_{r} \quad$ dimensional accuracy in roughing machining operation ( $\mathrm{mm}$ )

$D A_{U} \quad$ limit of dimensional accuracy $(\mathrm{mm})$

$F \quad\left\{F_{r}, F_{s}\right\}$, cutting forces during rough and finishing machining (kgf)

$F_{U} \quad$ maximum allowable cutting force $(\mathrm{kgf})$

$K_{o} \quad$ direct labour cost + overhead (\$/min)

$K_{t} \quad$ cutting edge cost (\$/edge)

$L \quad$ length of work-piece (mm)

$N \quad\left\{N_{r}, N_{s}\right\}$, spindle speeds for roughing and finishing machining (rpm)

$N_{j} \quad$ length of chromosome (binary string) of each design variable

$N_{r p} \quad$ number of rough passes

$P \quad\left\{P_{r}, P_{s}\right\}$, cutting powers during roughing and finishing machining $(\mathrm{kW})$

$P f_{i} \quad \%$ fitness of each chromosome

$P_{U} \quad$ maximum allowable cutting power $(\mathrm{kW})$

$Q \quad\left\{Q_{r}, Q_{s}\right\}$, chip-tool interface temperature constraints for roughing and finishing machining $\left({ }^{\circ} \mathrm{C}\right)$

$Q_{U} \quad$ maximum allowable chip-tool interface temperature ${ }^{\circ} \mathrm{C}$ )

$R \quad$ nose radius of cutting tool $(\mathrm{mm})$

$S C_{r} \quad$ stable cutting region for roughing machining

$S C_{s} \quad$ stable cutting region for finishing machining

$S C_{U} \quad$ limit of stable cutting region

$S R_{U} \quad$ maximum allowable surface roughness $(\mu \mathrm{m})$

$T \quad\left\{T_{n}, T_{s}\right\}$, expected tool-lives for roughing and finishing machining ( $\mathrm{min})$

$T_{u}^{\text {Norm }}$ normalized minimum production time

$T_{L}, T_{U}$ lower and upper bounds for tool life for roughing and finishing machining (min)

$T_{i} \quad$ machine idling time ( $\left.\mathrm{min}\right)$

$T_{m} \quad$ actual machining time ( $\left.\mathrm{min}\right)$

$T_{p} \quad$ tool life of weighted combination of $T_{r}$ and $T_{s}(\mathrm{~min})$

$T u_{u}^{\max }$ undesired production time estimate $(\mathrm{min})$

$T u_{u}^{\min }$ desired production time estimate ( $\mathrm{min}$ )

$T_{U t}^{N} \quad$ normalized production time for turning

$b_{i} \quad\left\{b_{i-1}, b_{i-2}, \ldots \ldots . . b_{0}\right\}$ binary string comprising genes

$d \quad\left\{d_{r}, d_{s}\right\}$, depth of cut in rough and finish machining operations (mm)

$d_{r} \quad\left\{d_{r L}, d_{r U}\right\}$, lower and upper bound of depth of cut in roughing machining $(\mathrm{mm})$

$d_{r t} \quad$ depth of cut in roughing for straight turning (mm)

$d_{s}\left\{d_{S L}, d_{s U}\right\}$, lower and upper bound of depth of cut in finish machining (mm) depth of material to be removed ( $\mathrm{mm}$ )

$f \quad\left\{f_{r}, f_{s}\right\}$, feed rates in roughing and finishing machining operations (rev/mm)

$f_{i j} \quad$ the $i^{\text {th }}$ objective function value in the $j^{\text {th }}$ position of the current population

$f_{i}^{\text {min }}$ the minimum ith objective function value

$f_{i}^{\max }$ the maximum ith objective function value

$f^{N} \quad\left\{f_{i}^{N}, f_{j}^{N}, f_{n}^{N}\right\}$, the $\mathrm{i}, \mathrm{j}$ and $\mathrm{n}$ normalized objective function values

$f_{r}\left\{f_{r L}, f_{r U}\right\}$, lower and upper bound of feed rate in roughing machining (rev/mm)

$f_{s}\left\{f_{s L}, f_{s U}\right\}$, lower and upper bound of feed rate in finishing machining (rev/mm)

$g_{i} \quad\{\mathrm{i}=1,2, \ldots, \mathrm{J}\}, \mathrm{J}$ numbers of inequality constraints

$h_{l} \quad$ constant relating to tool travel and approach/departure time $(\mathrm{min} / \mathrm{mm})$

$h_{2} \quad$ constant relating to tool travel and approach/departure time ( $\mathrm{min}$ )

$h_{k}\{\mathrm{k}=1,2, \ldots, \mathrm{K}\}, \mathrm{K}$ numbers of equality constraints

$k_{f} \quad$ constant pertaining to a specific tool-workpiece combination for cutting force and cutting power

$k_{q} \quad$ constant pertaining to the constraint of chip-tool interface temperature

$k_{r} \quad$ constant pertaining to the constraint of dimensional accuracy

$l \quad\left\{l_{v}, l_{d}, l_{f}\right\}$ lengths of range of the variables of cutting speed, depth of cut and feed rate

$l_{r} \quad$ run back length $(\mathrm{mm})$

$m$ number of objective functions

$n \quad$ number of rough cuts (an integer)

$n_{t} \quad$ an exponent that depends on cutting conditions

$n_{p} \quad$ population size

$n_{p t} \quad$ number of passes in roughing turning

$q\left\{q_{v}, q_{d}, q_{f}\right\}$ levels of precision of the variables of cutting speed, depth of cut and feed rate

$r \in(0,1)$ random number

$t_{c} \quad$ constant term( due to loading and unloading operations) ( $\mathrm{min}$ )

$t_{e} \quad$ tool exchange time ( $\left.\mathrm{min}\right)$

$v \quad\left\{v_{r}, v_{s}\right\}$, cutting speeds in rough and finish machining operations $(\mathrm{m} / \mathrm{min})$

$v_{r}\left\{v_{r L}, v_{r U}\right\}$, lower and upper bound of cutting speed in rough machining $(\mathrm{m} / \mathrm{min})$

$v_{s}\left\{v_{s L}, v_{s U}\right\}$, lower and upper bound of cutting speed in finish machining (rev/mm)

$w_{1} \quad$ weight coefficient representing the relative importance of production cost criterion

$w_{2} \quad$ weight coefficient representing the relative importance of production time criterion

$w_{1}^{*} \quad$ estimated value of $\mathrm{w}_{1}$

$w_{2}^{*} \quad$ estimated value of $\mathrm{w} 2$

$x \quad\left\{x_{1}, x_{2}\right\}$ lower and upper values of the variables

$x^{\prime} \quad$ integer value of the corresponding random binary string

$z \quad\left\{z_{v}, z_{d}, z_{f}\right\}$ binary string lengths of the variables

\section{Greek letters}

$\Phi_{t} \quad$ utility function of turning multi-objective model

$\alpha, \beta, \delta$ constants in the modified Taylor's tool life equation relating to cutting speed, feed rate and depth of cut

$\mu, v \quad$ constants relating to expression of cutting force and cutting power constraints

$\eta \quad$ machine efficiency

$\theta \quad$ a weight for $T_{p}[0,1]$ 
$\lambda, v \quad$ constants relating to expression of stable cutting region constraint

$\tau, \varphi, \delta$ constants relating to expression of chip-tool interface temperature constraint

$\chi, \varsigma, \psi$ constants relating to the dimensional accuracy constraint

\section{Acronyms}

CNC Computer Numerical Control

GAs Genetic Algorithms

\section{References}

1. Ahmad, R. S., 2004. Determination of Optimal Machining Parameters Using Goal Programming Technique. Conference proceedings, Society of Manufacturing Engineers, IMTS 2004. 1- 6.

2. Cus, F., Zuperl, U. and Gecevsku, V., 2007. High speed end-milling optimization using Particle Swamp Intelligence. Journal of Achievements in Materials and Manufacturing Engineering. 22(2): 75-78.

3. Borissova, D. and Mustakerov I., 2008. Multi-criteria Choice of Night Vision Devices Considering the Impact of Their Performance Parameters. AMO -Advanced Modeling and Optimization. 10(1): 81-93.

4. Marler, R. T. and Arora J. S., 2004. Survey of multiobjective optimization methods for engineering. Structural Multidisciplinary Optimization. 126(6): 369-395.

5. Lee, B. Y. and Tang, Y. S., 2000. Cutting parameter selection for Maximizing production rate or minimizing production cost multi-pass turning operations. Journal of Materials processing Technology. 105(1-2): 61-66.

6. Cus, F. and Balic, J., 2003. Optimization of cutting process by GA approach, Robotics and Computer Integrated Manufacturing. 19: 113-121.

7. Van Valdhuizen, D.A., Lamont, G.B., 2000. Multiobjective Evolutionary Algorithms. Analyzing the Stateof-the-Art. Evolutionary Computation. 8(2), 125-147.

8. Quiza-Sardinas, R., Santana, M. R. and Brindis, E. A., 2006. Genetic Algorithms-Based Multi-objective Optimization of cutting Parameters in Turning Processes. Engineering Applications of Artificial Intelligence. 19: 127-133.

9. Bouzakis, K. D., Paraskevopoulou, R. and Giannopoulos, G., 2008. Multi-objective optimization of cutting conditions in milling using genetic algorithms. Proceedings of the 3rd International Conference on Manufacturing Engineering (ICMEN). 763-773.

10. Kim, I. Y. and DeWeck, O. L., 2006. Adaptive weighted sum method for multi-objective optimization: a new method for Pareto front generation. Structural Multidiscipline Optimization. 31: 105-116.

11. Shimizu, Y., 1999. Multi-objective optimization for site location problems through hybrid genetic algorithms with neural networks. Journal of Chemical Engineering of Japan. 32(1): 51-58.

12. Deb, K., 1999. Multi-objective Genetic Algorithms: Problem, Difficulties and Construction of Test Problems. Evolutionary Computation. 7(3): 205-230.

13. Sankararao, B. and Gupta, S. K., 2007. Multi-objective optimization of an industrial fluidized-bed catalytic cracking unit (FCCU) using two jumping gene adaptations of simulated annealing. Computers and Chemical Engineering. 31: 1496-1515.

14. Goldberg, D. E., 1989. Genetic Algorithms in Search, Optimization and Machine Learning, Reading, MA: Addison-Wesley.

15. Amiolemhen, P. E. and Ibhadode, A.O.A., 2004. Application of Genetic Algorithms - Determination of the Optimal Machining Parameters in the Conversion of a Cylindrical bar stock into a continuous finished profile. International Journal of Machine tools and Manufacture. 140 (1-3): $340-345$.

16. Onwubolu, G. C. and Kumalo, T., 2002. Multi-pass turning optimization based on Genetic

17. Algorithms. International Journal of Production Research. 39(16): 3727-3745.

18. Amiolemhen P.E., Eseigbe J.A. 2019. Genetic algorithms solution to the single-objective machining process optimization time model. Journal of Mechanical and Energy Engineering, Vol. 3(43), No. 1, pp. 13-24.

19. Amiolemhen, P.E. and Ibhadode, A. O. A. (2019). Development of Genetic Algorithms based weighted method for multi-objective optimization. Journal of the Nigerian Association of Mathematical Physics. Vol. 35, pp. $149-154$.

20. Chen, M. C. and Tseng H. Y., 1998. Machining parameters selection for stock removal turning in process planning using a float encoding genetic algorithm. Journal of the Chinese Institute of Engineers. 16(4): 493506.

\section{Biographical notes}

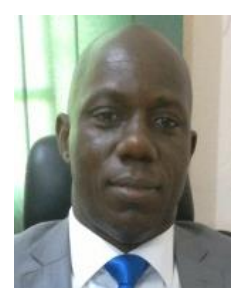

Patrick Amiolemhen is an Associate Professor in the Department of Production Engineering, University of Benin, Benin City. He holds a Bachelor of Engineering (B. Eng.) in Mechanical Engineering from the University of Benin, Benin City in 1991 and M. Eng. and $\mathrm{PhD}$ degrees in Production Engineering (Manufacturing Option from the University of Benin, Benin City in 203 and 2009 respectively. $\mathrm{He}$ is a certified mechanical engineer; a member of the Nigerian Society of Engineers as well as a member of the Nigerian Institution of Production Engineers. He has published both national and international journal articles. Since 2006 he has been a researcher in the Department of Production Engineering, University of Benin, where he teaches machines design; engineering mathematics; machine tool technology; operations \& production management at the undergraduate levels; while at the postgraduate level he teaches machines design; machine tool design; metal machining process optimization and human resources management. His present research areas focus on design and manufacture of engineering machineries and application of computational algorithms to multi-objectives optimization in engineering.

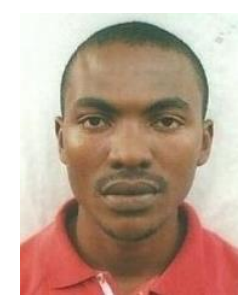

Joshua Eseigbe received his Bachelor's degree in Production Engineering from the University of Benin, Benin City Nigeria in 2012, and master's degree in industrial engineering from the same university in 2017. He is currently undergoing his doctorate degree in the Department of Production, University of Benin, Benin City. His research interests include; engineering design, optimization and industrial engineering. 